\title{
Time sharing at leisure facility centres: Analysis of sales performance indicators
}

Received (in revised form): 13 February 2008

\section{Rajagopal}

is Professor of Marketing at Monterrey Institute of Technology and Higher Education (ITESM), Mexico City Campus and Fellow of the Royal Society for Encouragement of Arts, Manufacture and Commerce, London. He has been listed with biography in Who's Who in the World, 2008. He holds a doctoral degree from Ravishankar University, India and has been conferred as National Researcher- Level-II of Mexican National System of Researchers. He teaches various topics of marketing in graduate, doctoral executive development programs of the Institute. Dr Rajagopal held key positions in many premier management institutes in India including Administrative Staff College of India.

\begin{abstract}
The changing cultural paradigms in Latin America have influenced a variety of leisure activities and significant implications for development of leisure services. Leisurespending behaviour prompts sequential relationship among customers intending to perform family celebrations in a different environment and gaining higher satisfaction through the customised services, recreational attractions and brand value. This study focuses on the qualitative dimensions associated with the sales people and managerial efforts made to augment the outcome performance in sales with reference to the time sharing proposals at leisure facility centres in Mexico. The leisure facility centres are used by individual and institutional customers for organising leisure events, parties and family gatherings. The study reveals that the leisure facility centre developer firms function with team sales strategy and the performance of sale teams is linked with their contributions to the profit of the firm.
\end{abstract}

\section{Keywords:}

\section{Rajagopal}

Professor and National Researcher, Department of Marketing Business Division,

Monterrey Institute of Technology and Higher Education (ITESM),

Mexico City Campus,

222, Calle del Puente,

Tlalpan,

DF 14380 , Mexico

Tel: +525554832251

Fax: + 525554832234

E-mail: rajagopal@itesm.mx, prof_rajagopal@yahoo.com Web: http://www.geocities.com/ prof_rajagopal/homepage.html team sales, customer satisfaction, sales performance, leisure property, brand image, returns on assets

Journal of Retail and Leisure Property (2008) 7, 248-262.

doi:10.1057/rlp.2008.11; published online 11 June 2008

\section{INTRODUCTION}

Selling and leasing activities of real estate and corporate infrastructure developers have greater dependence on financing institutions for making the resources available and governed by the inflation trend of the country. Corporate estate builders like Hines have business to business dealings and work with the technical sales force. The condition of real estate markets has been, and is likely to remain, an important determinant of 
credit risk for banks and thrifts. Sales in real estate markets have been a challenging task for developers and agents. In recent years, the repeatsales method has been widely used to construct constant quality property price indices. Since buildings depreciate over time, a simple repeat-sales index would underestimate the growth in property prices (Chau et al., 2005). The two types of shopping centre models are observed in the emerging real estate markets in developing countries, which are characterised by their ultimate relationship with the physical shopping centre on whose website they reside. Such selling models can be summarised as the centre-led approach and the brand-driven approach. Internet-based sales provide an important adjunct to conventional retail sales and are an important source of potential risk for landlords and tenants in the real estate investment market. Regardless of whether retailers use the internet as a sales channel, as a product-sourcing tool, or merely to provide information to the consumer, the internet has become a keystone within the greater retail marketing mix (Dixon and Marston, 2005). The real estate market in Mexico has undergone some significant changes over the recent past. It is, however, found that real estate markets are becoming difficult due to recession in investor liquidity and further decline in available mortgage financing. Compounding this situation is the fact that buying and leasing real estate in Mexico has historically been a cashdriven market. Mexico, however, presents a better future for real estate developers and sellers (Creekmore, 2001).

This study focuses on qualitative dimensions associated with the sales people and managerial efforts made to augment the outcome performance in sales with reference to the time sharing proposals at leisure facility centres in Mexico. The leisure facility centres are used by individual and institutional customers for organising leisure events, parties and family gatherings. The study also aims at analysing personality traits of sales people and linking the performance measures to physical factors in portraying the achievements of sales in the leisure property sector in price-sensitive markets. The relationships among the key performance variables, including team coordination, team leadership, task distribution and customer relationship, have also been examined in this paper.

\section{REVIEW OF LITERATURE AND FRAMEWORK OF HYPOTHESES}

Marketing efforts in commercial real estate lending need to occur in a coherent manner. To accomplish this, four areas need to be examined: the overall and local market areas; new customers; current customers and past customers. It is essential that commercial real estate lenders avoid Static Point Marketing — placing the product and the customer together at a fixed point in time. Marketing efforts should anticipate the customer's future needs in terms of products and services by having a probability associated with the needs that arise during various points in time. Marketing programmes should focus not only on the customer, but on the changing needs of the commercial real estate borrowers. These efforts should not exist independent of one another, but should be linked together. The information gathered in the four phases of collection needs to be integrated with operational data. It is only with the tying of the 
customer satisfaction data, customer contact information, market and economic information and competitive intelligence with the operational data that the true effects of the various factors may be quantified (Surovcik and Thode, 1998).

Ecotourism has been heralded as a potential economic and environmental saviour in much of Latin America, although explosive foreign investment in ecotourism ventures raises questions about the validity of ecotourism as a tool for sustainable local development. A research using three case studies from coastal Belize and the Bay Islands off the Honduras to illustrate the challenges that local communities face while attempting to derive ecotourism benefits, finds that there is marked cultural shift towards planning and politicisation of corporate ventures in Latin America and the Caribbean (Moreno, 2005). Selling real estate or leisure property is largely integrated with the place-marketing process. The industrial landscape is re-conceptualised as a future-oriented landscape of cosmopolitan residential and leisure lifestyle, as an expression of desire for professional occupancy. It has been observed in a study that local participation and influence in planning decisions of this public-private venture is somewhat marginal to economic considerations (Oakley, 2007). High expenses and rents or low expenses and rents are explicit strategies, positioning properties along with an efficient sales person as profit frontier. Instead of a rent-vacancy trade-off, the operator can select either gross or net rent, or some combination as an offset for vacancy. This macrostructure is more in keeping with observed real estate markets, where some managers focus on net operating income and others on effective gross income (Chinloy and Maribojoc, 1998). One of the studies explores the factors that affect service quality for a large residential real estate brokerage firm in a diverse mid-western city and the results indicate statistically significant relationships between both agent characteristics and the tangible aspects of the firm (Seiler et al., 2000).

The sales process of a leisure facility centre moves to conventional channels comprising estate agents and brokers, besides the sales executives of estate developer firms wherein both agents and brokers are paid by the seller based on a percentage of the sale price. It therefore creates substantial transactional inefficiencies for buyers and sellers at both the matching and bargaining stages of a transaction. While there is evidence that market forces are pushing for a change in the status quo, there is also evidence that the brokerage industry is resisting this change by pursuing anti-competitive policies and laws (Miceli et al., 2007). Such market conditions pull back sales efforts and shrink the performance of selling real estate and leisure property ventures. It has, however, been observed that leisure property prices increase within proximity to recreational parks, but there are generally less price effects from park proximity for lower density housing types. Thus, an open space policy may generate a strong influence on the scale and density of surrounding urban development (Dehring and Dunse, 2006).

The sales performance in an international context has emerged from significant managerial consideration in view of growing globalisation and the need to sustain competitive advantage (Magrath, 1997; Rajagopal, 2007). The value of relationship with the customer reveals significant 
quality and behavioural outcomes in the sales activities. Value displays a stronger impact on satisfaction than on commitment and trust, and also directly impacts a customer's intention to expand business with the firm. Perceived strength of the relationship with the customers may be measured by salespeople in reference to technical ability, experience, pricing requirements, speed of response, frequency of customer contact, degree of cooperation, trust, length of relationship, friendship and management distance barriers (Rajagopal, 2007). Such attributes lead toward the following hypothesis:

$\mathbf{H}_{\mathbf{1}}$ : Selling the time-share proposal of a leisure facility centre depends on effective team coordination towards prospective customers, closing deals and gaining competitive advantage in the market by offering satisfactory customer services.

Result-oriented control and market volatility are positively related to selling performance with reference to leisure time sharing at leisure facility centres. The effect of sales force adoption on selling performance is stronger where outcome-based control is used and where the firm provides information on the background of the new product to salespeople through internal marketing (Hultink and Atuahene-Gima, 2000). It has been observed that salespeople who simultaneously exhibit commitment and effort will achieve higher levels of new product selling performance. Improving our understanding of sales management control initiatives and their impact on salesperson and organisation consequences is a relevant management issue.

\section{The organisational culture of sales}

Leisure facility centre developers in Mexico earn their brand value by maintaining their integrity, professionalism, customer services and competitive prices. It is found that among the estate developer companies, top management executives provide strong leadership and an environment where creativity and customer services are encouraged as major sales drives. Sales people of the organisation strive to improve customer relationship and sales through tenant/client satisfaction and effective project promotion. A strong commitment to innovation, excellence and sound business practices, and a philosophy of long-term investment in human and financial resources enables the local facility centre developers to consistently attract and retain a fiercely dedicated, capable, performance-oriented workforce. Sales are driven by differences in beliefs about the valid scope and focus of activity, time focus, valid sources of knowledge, differences in perceived status and the relationship with the business environment. Recent research investigating customeroriented selling has indicated that greater attention needs to be focused on organisational or personal antecedents influencing customer-oriented selling behaviours (Martin and Bush, 2003). The environment of the sales department would include its goals, objectives and culture, as well as the behaviours, beliefs and attitudes of top and middle management. Expectations in a sales organisation are transmitted to its salespeople 
Table I: Services offered by leisure property developers

\begin{tabular}{|c|c|c|c|}
\hline Development & Asset/property management & $\begin{array}{l}\text { Acquisitions and } \\
\text { dispositions }\end{array}$ & Marketing and leasing \\
\hline Feasibility and economic analysis & Real estate and market assessments & Property evaluation & Market assessment \\
\hline Environmental and site evaluations, & Strategic planning, project positioning & Market analysis & Project assessment \\
\hline government approval and coordination & and repositioning & Strategic planning & Investment market assessment \\
\hline Budget development and administration & Acquisition/sales coordination & Risk analysis & Repositioning strategy \\
\hline Architectural and engineering contract & Project financing budgeting/accounting/ & Investor advise & Marketing plan development \\
\hline negotiation & control & Financing & Broker relations \\
\hline Conceptual construction & Property management & Closing & Tenant prospecting \\
\hline Design coordination & Facility management & & Lease negotiations \\
\hline Construction buyout & Marketing/leasing & & National tenant programme \\
\hline Scheduling accounting/control/reporting & Project development and redevelopment & & coordination \\
\hline Marketing and public relations & Public relations & & Public relation \\
\hline Construction management & Tenant relations & & \\
\hline Tenant construction management & Construction management & & \\
\hline \multirow[t]{6}{*}{ Operations and maintenance planning } & Energy management & & \\
\hline & Security & & \\
\hline & Tax analysis/administration & & \\
\hline & Parking administration & & \\
\hline & Risk management & & \\
\hline & Vendor contract negotiations & & \\
\hline
\end{tabular}

through its corporate culture and environment, who then implement the policies and carry out organisational strategies.

Leisure facility centre developer companies generally offer a full range of services to corporate and institutional real estate owners, including asset management, property management, marketing/leasing, development/redevelopment, acquisition/disposition, finance/accounting and engineering. Such firms work closely with each client to identify current needs and create innovative solutions to reach short and long-term investment goals and demonstrate value engineering attributes that allow its partners to achieve their development goals on or below budget. The activities of the property developer companies in Mexico are exhibited in Table 1.

Changing technology and markets have stimulated the team approach in multinational companies for performing organisational tasks. Furthermore, the complexity of the society and human needs devised to meet augmented needs have endorsed the team spirit as a significant tool in managing corporate tasks. Team management is employed largely in organisations where activities are less repetitive and predictable. Such an approach demands effective liaison, appropriate delegation of powers, judicious allocation of roles to team members, sharing of information and accuracy in the evaluation of team performance (Harris and Moran, 1999).

It is found during the study that many leisure facility centre development projects are undertaken as corporate ventures in collaboration with international firms and such strategy has become significant in view of the process of globalisation resulting in free trade and business development opportunities for multinational construction companies. Success is associated with high levels of commitment, competitive skills and dynamics in functional management of the venture. 
In the study the variables of economic and relational dimensions of external and internal fit have shown greater association with venture success. It has also been found that such ventures opt for greater autonomy and less economic dependency on their parent ventures for leading success and this finding make intuitive sense (Rajagopal, 2006). The success of corporate ventures in the leisure facility centre development sector in Mexico can be evaluated from the perspectives of economic, operational and managerial efficiency. The economic relationship concerns the degree of congruence between the practices of a parent company and its venture in reference to the issues of target scheduling and achievement, market share, returns on investment and profitability eventually. Hence it has been hypothesised that:

$\mathbf{H}_{2}$ : The operations of leisure facility centre development ventures are carried out on the basis of economic variables such as cost of construction, rate of return, market share and extent of profit.

The operational commitments in the leisure facility centre development venture reflect commitments in the form of large, specialised, recoverable investments. These factors are largely associated with the success of sales strategies of such ventures. It has been observed that occurrence of sunk costs in sales process is among the more common causes of losses in leisure facility centre time sharing deals (eg Block and MacMillan, 1993).

The study finds that the firms engage in acquisitive learning in order to build this new capability and adapt to the firm-specific context through experimential learning mechanisms. Corporate venture facility centre developer firms often rely heavily on their ability to develop firms around 'winning' ideas and too little on how they can promote a continuous flow of high quality ideas. One of the most challenging aspects of corporate ventures is finding the right people, and corporations must be willing to devote significant time and resources to working closely with their portfolio companies if they wish to gain satisfactory value from their external investments. Much, however, depends on the dynamics at which the leisure facility centre developer firms are evolving with the market in reference to the speed of technology and innovation concepts. By analysing these two factors, companies can improve their odds of succeeding as first movers with the resources they possess (Suarez and Lanzolla, 2005).

The team-selling approach is followed by many leisure facility centre developer firms towards rendering better customer services and delivering higher satisfaction. During this process the customer faces the buying challenge and the salespeople support such initiatives with comprehensive product information. The team selling would also be advantageous when an account requires special treatment or when a large number of people are involved in the process of buying decision. In addition, team selling is more likely to be employed when the potential sale is large for the representative firm and when the product is new to the product line of salespeople (Rajagopal, 2008). The sales results typically emerge from the performance of the salesperson and this issue is receiving increasing 
attention among multinational companies. This may be evidenced from research in several countries that indicates that sales managers are concerned with the team and customer relationship-building activities of salespeople as well as their sales results (Corcoran et al., 1995). Accordingly, the hypothesis has been framed as below:

$\mathbf{H}_{3}$ : Team sales practices help towards delivering quick and positive financial achievements, while good office practices followed in sales drive higher customer satisfaction.

Contemporary practices of selling high-technology and high-value products show that cross-functional team structures are pivotal for improving success rates. The cross-functional teamwork in sales-led or design-led structures delivers higher customer satisfaction and influences buying decision more than conventional sales approaches. The premise has been that team sales techniques are more participative, and more efficient than agent or broker-based sales strategies in selling capital goods like leisure property (Ainamo, 2007).

\section{THE STUDY DESIGN}

The study is based on 32 semi-structured interviews conducted with leisure facility centre entrepreneurs operating in Mexico City. The reference period of the study is 2002-2005. The leisure facility centres are used by individual and institutional customers for organising leisure events, parties and family gatherings. The features of leisure facility centres include bed rooms, a kitchen, recreation place for children, high speed internet, communication and audio-video equipments, a housekeeper and other leisure amenities. Time sharing in leisure facility centres is preferred for celebration of many family events like regular birthdays, 15th birth anniversary of girls and wedding receptions.

The interviewees had been managers of the leisure facility centres for at least two years. This was an important criterion for their selection as study participants. Each interview lasted between 2 and $3 \mathrm{~h}$. Principal issues deliberated during the interview are exhibited in the Appendix. The interviews played an important role in drawing attention to the sales strategies followed by developers of leisure facility centres in terms of promoting brand image, customer value and augmenting profit. The interview phase of the study was supported by an extensive review of literature on leisure property ventures and sales management, which served as the foundation for a detailed survey of practices and processes.

\section{RESULTS AND DISCUSSION}

The leisure facility centre developer firms in the study region provide responsive, professional asset and property management that is vital to the owner, investor satisfaction and tenant services. Firms are also closely involved in all aspects of the leasing process, from structuring and negotiating leases and brokerage agreements, to coordinating closing 
Table 2: Correlation matrix of the major variables under study

\begin{tabular}{llllll}
\hline Variables & $\begin{array}{l}\text { Task } \\
\text { coordination } \\
\text { among } \\
\text { sales teams }\end{array}$ & $\begin{array}{l}\text { Customer } \\
\text { prospecting }\end{array}$ & $\begin{array}{l}\text { Closing } \\
\text { deals }\end{array}$ & $\begin{array}{l}\text { Customer } \\
\text { services }\end{array}$ & $\begin{array}{l}\text { Developing } \\
\text { brand image }\end{array}$ \\
\hline Task coordination among & 1.000 & & & & \\
sales teams & $0.476^{*}$ & 1.000 & & \\
Customer prospecting & $0.652^{* *}$ & $0.872^{* *}$ & 1.000 & \\
Closing deals & $0.898^{* *}$ & $0.624^{* *}$ & $0.713^{* *}$ & 1.000 & \\
Customer services & $0.510^{*}$ & $0.492^{*}$ & $0.517^{*}$ & 0.284 & 1.000 \\
Developing brand image & & & & \\
\hline
\end{tabular}

p-values $*>0.01$ and $* *>0.001$

transactions, all the way to tenant move-ins. Among other variables used in the study, the task distribution has apparent impact on outcome performance in both the countries. One of the more persuasive reasons for inconsistent task distribution within teams is, however, the attribute of team members to deal independently outside the team frame to score an individual performance.

It is found in the study that quantitative performance measures require a detailed analysis of salespeople's call reports, an extensive time utilisation analysis, or even solicitation and evaluation of customer feedback on nonselling activities. Once the measurement procedure is set up, it is typically conducted with less bias and inconsistency in the teams. Correlations for all major variables of study exhibited in Table 2 indicate consistency with the hypothesis $\mathrm{H}_{1}$.

Redundancy in the results which exhibited some degree of bias in intercorrelations among variables has been minimised using Monte Carlo (MC) method. Bias is largely affected by sample size and bias was found to decrease by increasing the volume of data. As the data have been organised following normative distribution, in many observations, the bias of inter-correlations in results was minimised. Due to computational limitations of the data, the statistical prejudice could not be fully eliminated. The results are more likely to project a relationship from the perspectives of judgments and efficacy. The bias of illusory correlation effect on the judgment similarity of variables' relationship, or of whether the relationship of one variable induces another, has also been statistically minimised using the MC method. Theoretically, inter-correlation bias tends to decrease as the inter-correlations between the two sets of variables increase. The numbers of predictors and criterion variables, as well as the size of the correlations between variables in each set, has relatively minimal effect on bias (Beth, 1982).

Many of the respondents indicated that they used multiple milestones, including both financial and nonfinancial measures of performance. As such, control measures for the specific type of milestone(s) used could not be strictly applied. The relational measures included one single-stage question whether the parent company would withdraw support if the venture were to experience adverse conditions.

The variables with reference to the relational measures included the importance of venture culture, sense of autonomy and the role of 
Table 3: Mean Scores of the variables on economic dimensions

\begin{tabular}{|c|c|c|c|c|c|}
\hline \multirow{2}{*}{$\begin{array}{l}\text { Performance } \\
\text { dimensions }\end{array}$} & \multirow[t]{2}{*}{ Variables } & \multirow[t]{2}{*}{ Hypothesis } & \multicolumn{3}{|c|}{ Mean scores } \\
\hline & & & High & Low & Difference \\
\hline \multirow[t]{5}{*}{ Economic } & $\begin{array}{l}\text { Sales deliver optimum rate of returns to } \\
\text { the firm }\left(V_{1}\right)\end{array}$ & $\mathrm{H}_{2}$ & 4.15 & 2.77 & $1.38^{*}$ \\
\hline & $\begin{array}{l}\text { Sales offer competitive price and other } \\
\text { economic advantages }\left(V_{2}\right)\end{array}$ & $\mathrm{H}_{1}$ & 3.86 & 3.43 & $0.43 * *$ \\
\hline & $\begin{array}{l}\text { Services linked sales negotiations drive } \\
\text { higher market share }\left(V_{3}\right)\end{array}$ & $\mathrm{H}_{1}, \mathrm{H}_{2}$ & 4.31 & 3.97 & $0.34 * *$ \\
\hline & $\begin{array}{l}\text { Team sales strategies along with good office } \\
\text { practices deliver quick and positive financial } \\
\text { achievements }\left(\mathrm{V}_{4}\right)\end{array}$ & $\mathrm{H} 3$ & 4.22 & 2.40 & $1.82 *$ \\
\hline & $\begin{array}{l}\text { Profit contribution as a major factor towards } \\
\text { sales performance }\left(V_{5}\right)\end{array}$ & $\mathrm{H}_{2}, \mathrm{H}_{3}$ & 4.77 & 2.65 & $2.12^{*}$ \\
\hline \multirow[t]{3}{*}{ Relational } & $\begin{array}{l}\text { Decisions taken within the sales teams lead } \\
\text { to positive negotiations }\left(V_{6}\right)\end{array}$ & $\mathrm{H}_{1}, \mathrm{H}_{3}$ & 4.62 & 3.23 & $1.39 * *$ \\
\hline & $\begin{array}{l}\text { Customer satisfaction as major driver in } \\
\text { selling leisure property }\left(V_{7}\right)\end{array}$ & $\mathrm{H}_{1}, \mathrm{H}_{3}$ & 4.61 & 4.36 & $0.25^{*}$ \\
\hline & $\begin{array}{l}\text { Importance of cultural values associated } \\
\text { with the selling process }\left(\mathrm{V}_{8}\right)\end{array}$ & $\mathrm{H}_{1}, \mathrm{H}_{2}$ & 4.83 & 3.96 & $0.87^{*}$ \\
\hline
\end{tabular}

Superscripts indicate $p$ values for one-tailed t-tests $*<0.05$ and $* *<0.01$

managers in decision making. The mean score of the survey for the high and low performers with reference to the variables encompassing economic and relational dimensions has been exhibited in Table 3. The hypotheses have been evaluated with the help of multi-stage mean scores. The $p$-values for the difference between the high and low mean score show that economic variables including effective sales strategies delivering optimum rate of returns to the firm $\left(\mathrm{V}_{1}\right)$, team sales and good office practices which drive quick and positive financial achievements $\left(\mathrm{V}_{4}\right)$ and profit contribution towards sales performance $\left(\mathrm{V}_{5}\right)$ have been found at $<0.05$ level while the $p$ - values for the rest of the variables, $\mathrm{V}_{2}$ and $\mathrm{V}_{3}$, were found at $<0.01$ level. The $p$-values for the relational variables such as customer satisfaction $\left(\mathrm{V}_{7}\right)$ and cultural values associated with the selling process $\left(\mathrm{V}_{8}\right)$ have been found at $<0.05$ level while the $p$-value for the variable referring to whether decisions that are taken within the sales teams lead to positive negotiations $\left(\mathrm{V}_{6}\right)$ appeared at $<0.01$ level of significance.

The differences between the high and low sales performers have been found significant with reference to the rate of returns associated with the venture $\left(\mathrm{V}_{1}-\mathrm{H}_{2}\right)$, team sales strategies $\left(\mathrm{V}_{4}-\mathrm{H}_{3}\right)$, customer satisfaction $\left(\mathrm{V}_{7}-\mathrm{H}_{1}, \mathrm{H}_{3}\right)$ and cultural values associated with the selling process $\left(\mathrm{V}_{8}-\mathrm{H}_{1}, \mathrm{H}_{2}\right)$. Accordingly, results discussed in the Table 3 are found consistent with hypotheses $\mathrm{H}_{2}$ and $\mathrm{H}_{3}$.

It has been found that while working out the logistic regression, the value of the constant was found 1.63 and the $p$-value obtained for the same was $<0.01$ and the chi-square value for the data was 3.84 . The logistic regression analysis for variables is exhibited in Table 4. The results of logistic regression are also found consistent with hypotheses $\mathrm{H}_{1}$ to $\mathrm{H}_{3}$. Analysis of the survey results, however, showed that the higher sales performers relied more on the optimum rate of returns 
Table 4: Descriptive statistics and logistic regression for variable scores

\begin{tabular}{lllll}
\hline Hypotheses & Var $^{\mathbf{a}}$ & F-Test $^{\text {b }}$ & Probability $^{\mathbf{c}}$ & $\mathbf{R}$ \\
\hline $\mathrm{H}_{1}$ : Effective team coordination in driving selling process & 2 & 1.88 & 0.02 & $1.02^{*}$ \\
$\mathrm{H}_{2}:$ Sales performance and optimum rate of returns to the firm & 4 & 1.66 & 0.19 & $0.56^{* * *}$ \\
$\begin{array}{l}\mathrm{H}_{3}: \text { Team sales strategies and good office practices towards } \\
\quad \text { delivering quick and positive financial achievements }\end{array}$ & 4 & 1.91 & 0.09 & $0.57^{* * *}$ \\
\end{tabular}

andicates number of interactive variables used to evaluate hypotheses (eg $\mathrm{HI}$ evaluates pricing, investment in leisure property, quality of services, brand image, substitution effects, etc)

bF-test is derived from Hotelling's $T$-square formula $F=\left[(N-p-I / N-2) p t^{2}\right]$ wherein, $N=n_{1}+n_{2}$ represents total number of observations, $p$ indicates the total number of variables being analysed

'Probabilities are based on the null hypotheses, which explains that the mean vectors of the high and low performers are equal. $H_{0}: H i=L o$

Superscripts indicate $p$-value $*<0.05$ and $* *<0.01$

and considered profit as a major factor for stimulating innovation at the venture level. Satisfactory customer service has been considered one of the prime factors governing the success of the leisure facility centre ventures in Mexico. The relative difference between the low and high sales performance of the firms covered during the study has been compared through the null hypotheses because the rate of change among the low and high performers was equal.

Salespeople of the leisure firms comprehend the services available to the customers and brand value of the firm in evaluating and making hiring decisions in the leisure facility centres. Working closely with clients, the sales teams evaluate customer requirements, capital expenditures, leasing risks, returns on investment and competitive price. It is found that leasing represents the most significant area of risk and return for leisure facility centre owners, and has a proven ability to create and sustain leasing momentum. Many companies leasing leisure facility centres work with a large number of clients and adopt multilevel sales strategy by negotiating the deal with prospective customers. The new buyers are paid categorical attention by providing them with comprehensive information and generating a high level of satisfaction about the quality, brand and services of the company. The firms also follow the solution approach to problem clients and attempt to resolve the most secured solutions in real estates transactions.

\section{MANAGERIAL IMPLICATIONS}

An effective win-win situation can be acquired between leisure facility centre firms and customers by sharing services and brand value through offering long-term equity in the leisure facility centre. This would allow the venture managers to focus fully on the commissioning and ongoing sustainable operation of the new facilities to ensure productivity, cash flow and profitability of the business. The firm's reputation for the best performance needs to include:

- Superior building standards and systems design

- Responsive, professional and value-added property management for a variety of property types 
- Long-term ownership of major properties

- Consistently higher occupancy levels than market average

- High tenant satisfaction ratings

- Tenant retention rates that outscore competitors

- Efficient and cost-conscious operations with lower operating costs than other properties in the same markets

- Financial stability and conservative fiscal policies, with a debt to asset value ratio of less than 40 per cent

- Commitment to prime locations

- Maintenance of the highest standards of quality and service

- Strict adherence to best practices

As consumer satisfaction is one of the major drivers of sales performance towards prospective customers for buying time sharing proposals at leisure facility centres, sales teams need to be oriented towards providing high convergence of tangible and intangible factors to the customers during the sales process. A strategy paradigm for augmenting such an effect is exhibited in Figure 1.

There is increasing competition in developing countries like Mexico in the leisure property sector and leisure facility centres are emerging as low investment-high profit ventures. Hence, salespeople should focus on customer value, emphasising the design, technology and services innovation. The substitution effect of a customer intending to buy time sharing proposals of leisure facility centres can be lowered by offering higher competitive advantage.

Effects of sales drivers, which include territory design, compensation, task performance pattern and cultural interface, need to be optimised at the managerial level to inculcate higher perceived values on task management among the salespeople. Higher perceived values on the drivers among salespeople help in maximising the outcome performance in leisure facility centre developer firms. The high-performance

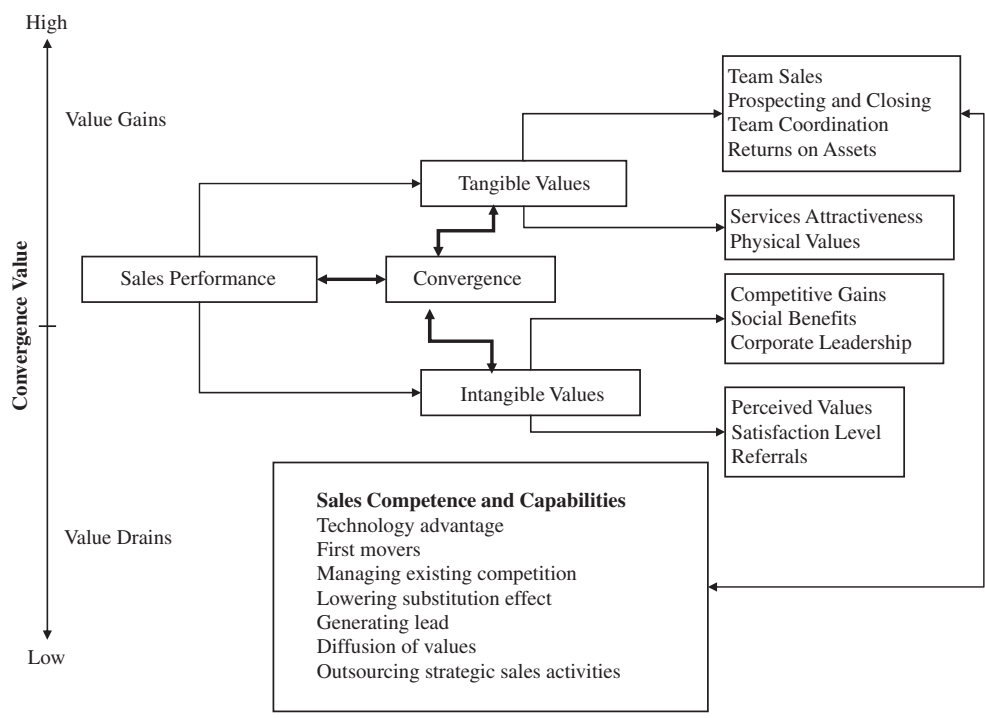

Figure I: Customer value architecture and sales performance 
salespeople have greater commitment to their organisations and their sales managers are more satisfied with their units' sales territory designs. The mangers may need to re-conceptualise the fact that the salespeople should shift from a 'hard selling' to a 'smart selling' approach. The SMART variables may be considered to administer sales teams strategy orientation, measurability, approach, reality and time-frame. The strategy orientation would drive the brainstorming discussion to resultorientation and the measurability would count on the success of the deliberations (Rajagopal and Rajagopal, 2006). Teams, which need to work within an organisation and across functional activities such as sales, marketing, purchasing, personnel and finance find that team working fosters a collaborative rather than a competitive approach. It is important that terms of reference of teams must be capable of doing the job for which they have been selected and this clearly implies that the membership should include people that are able to contribute towards the completion of a task (McGreevy, 2006).

In the study the variables of economic and relational dimensions of external and internal fit have shown greater association with team performance. It has also been found that teams opt for greater autonomy for enhancing performance. Results of this study reveal that team performance largely depends on the effectiveness of team coordination, leadership and profit-linked sales performance. Effective coordination of tasks in a team is a consistent predictor of salespeople's performance and effectiveness in selling capital goods like leisure facility centres in a price-sensitive market. Leisure facility centre developer firms may also plan for customer convenience strategies such as password-protected portals in the new facility centre websites, which could allow tenants to contact the facility centre management electronically for maintenance and other needs, automatically generating work orders. These leisure facility centre portals offer security functions as well, allowing tenants to authorise specific visitors, speeding clearance with building security personnel. The sites also enable facility centre managers to deliver minute-by-minute building news to tenants. Such news can include information about special events, parking, building maintenance activities, street closings, security updates and more.

\section{CONCLUSION}

The study reveals that leisure facility centre developer firms function with team sales strategy and the performance of sale teams is linked with their contributions to the profit of the firm. The balance of strategies among team design, coordination, performance and managerial control are normally based on salespeople's outcomes, linked to the profit contribution to the firm. It may be appropriate for the managers to consider review of team designs for improving the sales performance. The results of the study show that the impact of buyer-seller codependency and relationship quality significantly affects the sales performance. It has been argued in the paper that service quality and the extent of buyer satisfaction are positively associated with the performance of salespeople including outsourced agents and brokers. Previous research 
studies on buyer-seller relationships in leisure facility centre markets as reviewed in the paper have shown that both buying and selling processes need to establish mutual trust, commitment and loyalty. The results of the study are consistent with the findings of previous studies referred in the paper and this paper attempts to contribute significantly to the existing studies as there is paucity of literature on this subject, particularly in reference to Latin America. This study being empirical in nature has, however, some limitations in reference to sampling, data collection and generalisation of the findings due to the small size of samples drawn for the study.

\section{Acknowledgement}

I sincerely thank Ruben del Rió, Roland von Blucher and Scott McGahey, participants of the course on Advanced Selling Systems (Jan-Apr) 2002 at ITESM, Mexico City Campus, who helped in collecting basic data on this project. I extend my sincere thanks to Amritanshu Rajagopal, student of Industrial and Systems Engineering in the campus, who worked on the advanced stage of data collection during 2004-05, data analysis and tabulation.

\section{References}

Ainamo, A. (2007). Coordination mechanisms in cross-functional teams: A product design perspective. Journal of Marketing Management. 23(9-10), 841-860.

Beth, K.D.-S. (1982). Correcting for BIAS in the Canonical Redundancy Statistic. Educational and Psychological Measurement. 42(1), 131-143.

Block, Z. \& MacMillan, I.C. (1993). Corporate Venturing: Creating New Business within the Firm, Harvard Business School Press, Cambridge, MA.

Chau, K., Wong, S. \& Yiu, C. (2005). Adjusting for non-linear age effects in the repeat sales index. Journal of Real Estate Finance and Economics. 31(2), 137-153.

Chinloy, P.T. \& Maribojoc, E. (1998). Expense and rent strategies in real estate management. Journal of Real Estate Research. 15(3), 267-282.

Corcoran, K.L., Peterson, L.K., Baitch, D.B. \& Barren, M.E. (1995). High Performance Sales Organizations: Creating Competitive Advantage in the Global Marketplace, Irwin, Chicago, IL.

Creekmore, M. (2001). Mexico real estate market. Arizona Journal of Real Estate and Business, May, 2001.

Dehring, C. \& Dunse, N. (2006). Housing density and the effect of proximity to public open space in Aberdeen, Scotland. Real Estate Economics. 34(4, Winter), 553-566.

Dixon, T. \& Marston, A. (2005). Taking the shopping centre online: New models in e-commerce. Property Management. 23(2), 97-109.

Harris, P.R. \& Moran, R.T. (1999). Managing Cultural Difference - Leadership Strategies for a New World of Business, Gulf Publishing Company, Huston, TX, pp. 106-273.

Hultink, E.J. \& Atuahene-Gima, K. (2000). The effect of sales force adoption on new product selling performance. Journal of Product Innovation Management. 17(6, November), 435-450.

Magrath, A.J. (1997). From the practitioner's desk: A comment on personal selling and sales management in the new millennium. Journal of Personal Selling and Sales Management. 17(1), 45-47.

Martin, C.A. \& Bush, A.J. (2003). The potential influence of organizational and personal variables on customer-oriented selling. Journal of Business and Industrial Marketing. 18(2), 114-132.

McGreevy, M. (2006). Team working: How are teams chosen and developed? Industrial and Commercial Training. 38(7), 365-370.

Miceli, T., Pancak, K. \& Sirmans, C. (2007). Is the compensation model for real estate brokers obsolete? Journal of Real Estate Finance and Economics. 35(1), 7-22.

Moreno, P. (2005). Ecotourism along the Meso-American Caribbean reef: The impact of foreign investment. Human Ecology. 33(2, April), 217-244. 
Oakley, S. (2007). Public consultation and place-marketing in the revitalisation of the Port Adelaide waterfront. Urban Policy and Research. 25(1), 113-128.

Rajagopal (2006). Innovation and business growth through corporate venturing in Latin America: Analysis of strategic fit. Management Decision. 44(5), 703-718.

Rajagopal (2007). Sales management in developing countries: A comparison of managerial control perspectives. Journal of Asia Pacific Business. 8(3), 37-61.

Rajagopal (2008). Organizational buying and sales administration in the retail sector. Journal of Retail and Leisure Property. 7(1), 3-20.

Rajagopal \& Rajagopal, A. (2006). Trust and cross-cultural dissimilarities in corporate environment. Team Performance Management-An International Journal. 12(7-8), 237-252.

Seiler, V.L., Webb, J.R. \& Whipple, T.W. (2000). Assessment of real estate brokerage service quality with a practicing professional's instrument. Journal of Real Estate Research. 20(1-2), $105-117$.

Suarez, F.F. \& Lanzolla, G. (2005). The half truth of first mover advantage. Harvard Business Review. 83(4), 121-127.

Surovcik, G.R. \& Thode, S.F. (1998). An integrative customer and competitive marketing information system for commercial real estate lendingWorking Paper, Marketing Solutions Corporation and Lehigh University, July 1998.

\section{APPENDIX}

\section{Principal Questions Administered To The Respondents}

\section{Economic Variables}

1. What are the major economic variables that influence buyer's decision on time-sharing proposals of leisure facility centre?

2. In your view, does the success of a leisure venture depend on achieving the optimum rate of returns?

3. Do you think that meeting sales targets of the leisure ventures is one of the significant determinants towards contributing profit to the firm?

4. How do you describe the significance of optimum level of investment in your leisure venture?

5. Does the customisation in the leisure venture augment customer value and help to achieve higher sales?

6. What is the role of team sales strategy in driving sales of the leisure venture?

7. In your view how significant is the marketing mix in managing the leisure venture economy?

8. Describe the good office practices in selling time sharing proposals of leisure ventures.

9. What should be the appropriate strategies for driving customer-tocustomer business and building the brand of your leisure venture?

10. Which factors drive the innovation and improvements in a leisure venture?

11. Are sales a major determinant in driving team performance?

12. Describe the process of outsourcing sales activities through agents and brokers.

13. Do you realise substitution effect among customers lowering the growth in sales of leisure services?

14. In you opinion, how do sales promotions help in retailing the leisure services?

15. What is the role of a manager of the leisure facility centre? 


\section{Relational Variables}

1. Describe the workplace culture in your leisure venture.

2. Do you prefer to work individually or in a team? Offer rationale for your answer.

3. Describe the process of decision making to augment sales and services value.

4. How effective is the decision making by teams in your venture?

5. What type of conflicts do you encounter in working with teams?

6. Describe your views on good office practices for achieving success?

7. How would outsourcing of salespeople help the economy of leisure ventures?

8. What are the major factors associated with customer-salespeople culture?

9. Do you think that knowledge sharing would be a beneficial process in developing favourable working environment leading to success?

10. In your view, what is the significance of cultural values in managing a leisure venture successfully? 